\title{
Modern views on the role and place of gerontological rehabilitation in the nation's
} health improvement system

\section{PROKOPCHUK Yulia ${ }^{1}$, VOLYANSKAYA Veronika ${ }^{1}$, SERAFIMOVA Elvira ${ }^{1}$, GUSHCHA Sergey ${ }^{2}$, PLAKIDA Alexander ${ }^{3}$}

\section{Corresponding author: PLAKIDA Alexander, E-mail: aplakida@mail.ru}

1 Special specialized clinical sanatorium named after V.P. Chkalov, Ministry of Health of Ukraine», Odessa, Ukraine 2 State Institution «Ukrainian Research Institute of Medical Rehabilitation and Balneology of the Ministry of Health of Ukraine», Odessa, Ukraine

3 Odessa National Medical University, Odessa, Ukraine

\begin{abstract}
The article discusses the aging process (theory of aging, mechanism, concept of the aging process, physiological and functional changes that negatively affect the condition of a patient with a gerontological profile). Geriatric rehabilitation is discussed, including physical (professional geriatric rehabilitation based on rehabilitation centers) and mental rehabilitation. It is shown that medical and psychological rehabilitation, which includes psychocorrection and psychotherapy, is essential. The paper assesses the rehabilitation possibilities (rehabilitation algorithms involving both natural and preformed physical factors) in gerontological patients suffering from various somatic diseases
\end{abstract}

Keywords: aging, geriatric rehabilitation, medical and physical rehabilitation, medical and psychological rehabilitation,

\section{Introduction}

One of the urgent social, medical, political, demographic problems of modern society's life is a significant increase in the life expectancy of a person. The average life expectancy globally is 72 years ( 70 for men and 75 for women $(1,2,3)$. In Ukraine, the average life expectancy is 71.98 years. Still, the total life expectancy in Ukraine is significantly lower than in social and economically developed countries of western Europe, where it is 80.3 years (4). Aging is a polyetiological process caused by genetically determined metabolic characteristics, diseases, an increase in the number of free radicals, the accumulation of nitrogen compounds, lipid peroxide products, xenobiotics, hypoxia, etc. Modern medical science pays exellent attention to the problem of aging; the emergence of new facts allows a deeper understanding of the mechanisms of this process. Today there are several theories of aging, which partly contradict each other, and partly supplement.

The most famous concepts of aging today are an accumulation of mutations, hormonal and genetic; mitochondrial; epigenetic; free radicals, somatic mutations; evolutionary-genetic, etc. $(5,6,7,8,9)$.

To better understand of the aging process, it should be noted that aging begins at the moment of conception and continues until the end of life. The stages of aging of the organism reflect the organism's genetically determined ability to adapt and compensate for losses from pathological processes. With age, all body systems show a decrease in performance. Today it is customary to divide the aging process into several periods conventionally: early - from 68 to 74 years old) middle from 75 to 84 years; and later - over 95 years old.

With age, there is a decrease in functional systems' performance of; that is, people are less able to withstand external influences and changes in internal needs. Human aging is assessed by a spectrum of physiological changes that contribute to the death's risk by reducing the functional systems' activity, which makes the body more susceptible to many diseases (10). Population aging in terms of demographic mortality rates is growing exponentially $(11,12)$. The decrease in the capabilities of human functional systems with age tends to a linear relationship and is characterized by gradual changes, such as:

- decrease in height and weight due to loss of muscle and bone mass;

- slowdown and changes in metabolism

- an increase in the time for the implementation of reactions;

- decreased memory functions;

- deterioration of kidney function

- suppression of immune function;

- decrease in physical performance;

- numerous endocrine changes. 
The above features of structural and physiological changes in the body of the elderly or senile age make it necessary to consider when developing rehabilitation measures to restore the state after a disease, and form a particular section of rehabilitation - geriatric rehabilitation. (13). Geriatric rehabilitation is understood as a set of measures aimed at maintaining independence, improving the quality of life and emotional well-being $(14,15)$. The goal of geriatric rehabilitation is to reactivate, resocialize, and reintegrate the patient.

Reactivation - measures aimed at restoring physically and socially inactive people's activity, increasing daily activity in their environment.

Resocialization - measures aimed at restoring contact with the family and getting out of isolation.

Reintegration is the return of an older person to society. One of the areas of geriatric rehabilitation is medical rehabilitation, which includes physical and psychological rehabilitation. In turn, physical rehabilitation consists of remedial gymnastics, occupational therapy, physiotherapy, etc. The most accessible for older people are light physical exercises, which include: morning exercises, remedial gymnastics, industrial gymnastics, dosed use of elements of outdoor games and sports.

Physiotherapy is one of the most effective areas of rehabilitation therapy. Physical therapy under the guidance of a physician or methodologist can treat almost all chronic diseases. However, an indispensable condition, is a correct dosage, strict consideration of both the patient's well-being and objective indicators of the body's systems' functional state, primarily the cardiovascular system.

Massage is another type of physical rehabilitation for the elderly. The most widely used therapeutic and hygienic massage, most often in combination with physiotherapy exercises.

Psychological rehabilitation is made up of both drug methods and various types of psychotherapy.

Gerontological care includes three areas: diagnosis, interventions, outcomes. Social rehabilitation means resocialization, that is, the return of the elderly to society, overcoming their isolation, social activity of the elderly and older people and expanding of their social contacts. For this purpose, both traditional sources of assistance (state social assistance systems) and informal sources are used - family members, friends, neighbors, voluntary and charitable organizations (16). An essentional part of social rehabilitation is spiritual rehabilitation, the meaning of which is to provide spiritual support to the elderly.

Educational geriatric rehabilitation is an introduction to older people about the processes taking place in their body, about the possibility of self-help, and sources of support. This impacts the older person in the direction of increasing his confidence in his abilities through the acquisition of new experience and new knowledge. The mass media are of great importance, as they can raise older people's educational level, inform about the general problems associated with aging, and form a positive image of older people in society.

Professional geriatric rehabilitation includes maintaining more prolonged possible working capacity, organizing a retraining system of and training for the elderly based on rehabilitation centers, providing jobs for the elderly, and involving pensioners as widely as possible in socially significant activities $(15,16)$.

It should be noted that this division into types is rather arbitrary: the individual components are interrelated and complement each other. The ultimate goal of all these activities is to restore independence in physical, mental, social, and professional relationships and improve older people's quality of life and well-being of.

In terms of duration, geriatric rehabilitation is carried out: in acute conditions, in subacute conditions, and longterm.

Basic principles of rehabilitation of elderly people

1. Early initiation of rehabilitation measures, which should complement and enrich the main therapy.

2. Stages of rehabilitation.

3. Continuity and continuity of rehabilitation measures as one of the basic and mandatory conditions for the effectiveness of treatment.

4. The complex nature of rehabilitation.

5. An individual approach to the preparation of rehabilitation programs. An individual profile must be established for each patient.

6. Risk factors, physical and mental characteristics, emotional reactions to the disease.

At each stage of rehabilitation, a program is drawn up, to identify the reserve capabilities of the body and help the patient achieve a high level of working condition. The psychological component includes studies of psychophysiology, intellectual and anamnestic characteristics, and the system older people's relations to restore, maintain and correct them. It is also expected to work with the family of patients. The principles of psychocorrectional work include the following:

- group approach;

- improved mood;

- reducing anxiety;

- increased self-esteem;

- the possibility of self-realization;

- the motivation for social activity, improving communication skills;

- adaptation up to date.

Considering the the elderly and senile age's psychological characteristics, the preference is given to group forms of work. Psychological rehabilitation for any somatic disease is aimed at different levels of the patient's mental 
organization and psychological components included in the etiopathogenesis of the disease.

1. Influence on the neurotic component of a somatic disease (functional and dynamic changes accompany all somatic diseases).

2. Influence on the mental component of a complex of etiological factors.

3. Influence on the patient's personality to change his reaction to the disease, correct the "scale of the experience of the disease", to improve its functioning in the new conditions of somatic disease.

Traditionally, much attention is paid to the diagnosis and correction of cognitive processes in the elderly. The socio-economic component affects aspects of lifestyle changes. The professional component aims to restore production skills impaired due to injury or illness; in case of loss of professional ability to work - stable or partial the patient can be prepared to learn a new profession. As for medical rehabilitation, it is carried out both using traditional medicine and by alternative means. The latter includes physiotherapy exercises, physiotherapy, occupational therapy and household rehabilitation, diet therapy, phytotherapy, reflexology, manual therapy, aromatherapy, bioresonance therapy, psychotherapy, and psychocorrection.

When prescribing physical methods of treatment, it is necessary to consider the characteristics of the aging organism and, first of all, the cardiovascular system, changes in its reactivity. Before the appointment of hardware physiotherapy and balneological procedures, a thorough clinical examination should be carried out, including studying of the function of the cardiovascular system. It should be borne in mind that any types of treatment by physical methods exert not only local but also general effects through the central nervous system, often require the mobilization of significant reserves, which the body of an elderly and especially an older person, as a rule, does not have. Great care should be taken with all types of hydrotherapy, although most elderly patients tolerate coniferous, iodine-bromine, oxygen baths, worse carbonic baths. And also, underwater massage is quite a big load for the elderly.

Thermal irritants in the elderly and older people cause feeble and delayed compensatory reactions of the skin capillaries. They are often inadequate and even paradoxical, and in response to the action of a thermal stimulus, not expansion but narrowing of the peripheral vascular network is observed. As a rule, drug electrophoresis, ultrasound treatment with the introduction of drugs through the skin, local application of UHF therapy, Bernard currents (diadynamic) in reduced doses are well tolerated. As an equivalent of a course treatment with injections of a $2 \%$ solution of novocaine, introducing of a $5 \%$ solution of novocaine by electrophoresis (from the positive pole) can be recommended. The method of choice is magnetotherapy, one of the most favorable and fairly easily tolerated methods of physical treatment against the background of natural physiotherapeutic factors (17).

Physical therapy methods play an essential role in preventing premature aging and treating of diseases, especially during the rehabilitation period. While the usual ways of drug therapy and rehabilitation often lead to the development of intoxication, allergic reactions, methods of physical rehabilitation, as a rule, allow avoiding this danger (18).

The following features of rehabilitation in geriatrics have been identified:

- the processes of readaptation in old age are slower; therefore, rehabilitation requires more time.

- compensatory opportunities are limited; therefore, rehabilitation programs must be adequate.

- an advantage in the rehabilitation of the elderly is given to non-drug types of a restorative treatment since intoxication and allergization develop faster with age.

Along with traditional methods of physiotherapy, magnetic field treatment, thermal therapy, hydrotherapy, classical massage, physiotherapy exercises, the rehabilitation program includes occupational therapy, group and individual forms of psychocorrection, and psychotherapy (19).

Occupational therapy is an active method of restoring and compensating for impaired functions through various work to create a useful product. In occupational therapy, the affected systems' very process of functioning acts as a therapeutic and restorative factor (20). According to the main tasks, means, and methods, the following occupational therapy types of are distinguished.

Reinforcing occupational therapy is a means of increasing the patient's general vitality and creates the psychological prerequisites for readaptation.

Household occupational therapy. It is carried out with patients who have suffered from acute cerebrovascular accidents, aggravated by paresis of varying severity, and patients who have senile dementia. Household rehabilitation should be started as early as possible since its goal is to eliminate the helplessness of the patient through sequential training in various activities, differentiated in complexity, in the field of self-care.

Rehabilitation occupational therapy impacts on the damaged part of the body, organ, or system to restore the function disturbed by the pathological process with appropriately selected types of labor activity.

Recreational occupational therapy - reducing the severity of aggravating factors caused by the forced extended stay in bed or a medical institution. It has a wide variety of forms, can be both entertaining and educational. The method's attractiveness is in the ease of use and low material costs in the organization; availability of use at all stages of rehabilitation. 
Physiotherapy exercises are central to the physical rehabilitation of the elderly as the most biologically based method of treatment. Regular exercise has a positive effect on the work of all organs and systems. The cardiovascular system has great reserve capabilities, due to which the risk of cardiovascular diseases is reduced. Respiratory system - more active use of oxygen by body tissues, slowing down the processes of reducing lung tissue elasticity. Metabolism - the content of cholesterol and triglycerides in the blood changes for the better. Mental sphere - activation of mental activity; beneficial effect on mood; reducing anxiety and increasing interest in the world. Maintaining independence in everyday life depends primarily on mobility, which is determined by the performance of muscles, bones, and joints. Physical exercise will help develop strength, flexibility, endurance, which is vital for a person leading an independent lifestyle.

Physiotherapy is the practice of geriatrics is becoming important. At present, many author's complexes and programs of physical exercises of a health-improving orientation have been developed and practically tested, which are intended for widespread use. Their main advantages are availability, ease of implementation, and efficiency. These are, first of all: controlled running loads (Cooper system), 1000 movements (Amosov system), 10,000 steps per day (Ikai system), running for life (Lidyard system). (21, 22, 23).

The most common exercises are walking, walking. Habitual physiological exercises are the best loads that a person can cope with more easily. It would help you if you started with walking (Scandinavian or straightforvard), where there are multidirectional movements of the arms and legs, and it is necessary to control the pulse. The calculation formula is universal 220 minus age. The pulse must be measured not only before, during, but also after the session. It is normal if the heart rate dropped 5 minutes after exercise approaching the initial value.

The health-improving effect of physical exercise is observed when it is rationally balanced by the capabilities of the patient. The systematic result of adequate physical activity on the human body leads to structural and functional restructuring, characterized by some psychological and physiological effects. Regular use of physical exercises and hardening factors increases the vitality of the body and natural immunity, improves the functions of the autonomic systems, efficiency and prevents premature aging.

In a complex of gymnastic exercises for the elderly, it is most useful to first perform gymnastics for the neck, which improves blood circulation in the brain stem. Therefore, local hypodynamia of the cervical spine is unfavorable for this category of patients (24). In atherosclerosis, the vessels lose their elasticity, become stiff, and are difficult to adapt blood pressure fluctuations(25).

It is tough for many people who are still not old, to bend over, wash the bathtub, pick up a fallen object from the floor and get something from a low bedside table. This is due to limitations in the flexibility of the spine. Subsequently, limited joint mobility can cause the development of one or another orthopedic disease. Therefore, every day, regardless of age, it is necessary to perform exercises that will help develop and maintain joint mobility and thereby help prevent the development of pathological processes in them. These exercises should be performed before the onset of mild fatigue, increasing the number of repetitions and range of motion from session to session.

In addition to complexes of physical exercises in the doctors' arsenal of from rehabilitation medicine, there are also various massage, mechanotherapy, preformed and natural physical factors (26).

In geriarthria, an integrative approach to palliative care is essential. Palliative care for the elderly should include specialized services and organizations. To work with this special group of patients, specialists who have received appropriate training are needed (27).

Psychocorrection and psychotherapy are important components of medical and psychological rehabilitation, aimed at full or partial restoration of the patient's personal and social status. Group forms of psychotherapy are the most appropriate method of psychological rehabilitation. Group psychotherapy, more than any other psychosocial influence method, contributes to the restoration of the system of relations between elderly patients with the microsocial environment, bringing value orientations following the way of life. There are two types of group methods of psychotherapy and sociotherapy in rehabilitation.

1. Therapeutic procedures aimed at the patient's social behavior, communication skills, self-realization, solving psychological problems and overcoming social conflicts.

2. The optimal is the organization of group of patients' social structure, based on the so-called environmental groups: functional groups, patients' club. These sociotherapeutic groups are focused on the social activation of patients and their involvement in society, promote communication training and instill in patients good behavior skills. They provide a corrective social climate to relive interpersonal relationships.

Relaxation techniques. Relaxation refers to the state of wakefulness, characterized by a decrease in psychophysiological activity, manifested in the whole organism or any of its systems. The clinical application of relaxation techniques has proven to be very useful in the treating of excessive stress and its clinical manifestations. The constant practical application of relaxation techniques can help reduce general anxiety. 
Behavioral therapy is a treatment that uses teaching principles to change behavior and thinking. Behavioral therapy is based on a psychological model of social learning and a commitment to the scientific method. Terence Wilson highlights the following provisions in this regard (28).

1. Many cases of pathological behavior, from the point of view of behavioral therapy, are non-pathological "life problems". These include, first of all, anxiety reactions, sexual deviations, behavior disorders.

2. Pathological behavior is mostly acquired and maintained in the same ways as normal behavior.

3. Behavioral diagnostics focuses more on the determinants of real behavior than on past life analysis. A person can be better understood, described, and evaluated by what he does in a particular situation.

4. Therapy requires a preliminary analysis of the problem, the allocation of individual components in it. These specific components are then systematically exposed to behavioral procedures.

5. Treatment strategies are developed individually for different problems in different individuals.

6. Understanding the origin of the psychological problem is irrelevant for implementing of behavioral changes; success in behavior change does not imply knowledge of its etiology.

Behavioral therapy is based on a scientific approach. This means that it starts from a clear conceptual framework that can be tested experimentally; treatment is consistent with the content and method of experimental clinical psychology; the technologies used can be described with sufficient accuracy to be measured objectively or to be replicated; therapeutic methods and concepts can be evaluated experimentally. Behavioral therapy seeks to provide the patient with a so-called "remedial learning experience". This learning experience involves the acquiring of new behavioral strategies, increasing communicative competence, overcoming maladaptive stereotypes and destructive emotional conflicts.

And, finally, the sanatorium-resort stage, the issues of this treatment are always resolved individually. Sometimes, after a thorough examination, the patient is sent to the resort even with contraindications to use the main therapeutic factor of the resort to use other healing effects. For example, this resort's hydrogen sulfide baths are contraindicated for a patient, but climatotherapy is not contraindicated. An essential difference in geriatric rehabilitation is the constant need to restore lost functions, the formation of optimism, getting it out of depression, and restoring status in the family, work, and society. The well-established idea of the possibility of sending people over 60 for rest and treatment only to resorts near their place of residence, the inadmissibility of using the methods of intensive balneotherapy, although it remains in force, in many cases no longer satisfies either the doctor or the patient.

This applies mainly to persons under the age of 65-70 with chronic diseases for which the most effective therapy can often be carried out in resorts, the climate of which is different from the local one and requires adaptation. Before deciding to send an older person to a spa treatment, it is necessary to conduct an extensive particularly thorough clinical study using various functional diagnostics methods and correctly assess the functional capabilities of the body.

Meteopathology - the study of adverse reactions of the body associated with changes in climatic and weather factors, is one of essential sections of climatology, is of particular importance in geriatric practice. The frequency of meteopathic reactions in humans increases significantly with aging. This explains why so many elderly and senile people develop meteorological stability.

Rehabilitation care is an important and integral part of the therapeutic process of treating gerontological patients. Therefore, the organization of rehabilitation moments for patients with a gerontological profile is one of the most challenging and still unresolved problems.

Conclusions. The relevance of gerontological patients' rehabilitation is mostly due to the need to expand the measures and capabilities of gerontological rehabilitation itself, which is based on physiological and functional changes in the state of health of patients. A multidisciplinary conceptual approach is needed - the combined use of factors of rehabilitation medicine in gerontological patients.

\section{References:}

1. Aburto JM, Villavicencio F, Basellini U, Kjærgaard S, Vaupel JW. Dynamics of life expectancy and life span equality. Proceedings of the National Academy of Sciences. 2020;117(10):5250-5259;doi:10.1073/pnas.1915884117

2. Foreman KJ, Marquez N, Dolgert A, Fukutaki K, Fullman $\mathrm{N}$. et al. Forecasting life expectancy, years of life lost, and all-cause and cause-specific mortality for 250 causes of death: reference and alternative scenarios for $2016-40$ for 195 countries and territories Lancet 2018; 392: 2052-2090.

3. Lenart P, Kuruczova D, Joshi PK. et al. Male mortality rates mirror mortality rates of older females. Sci Rep. 2019;9, e10589. https://doi.org/10.1038/s41598-019-47111W

4. Shevchuk P. Life expectancy in metropolises in Ukraine in the beginning of the XXI Century. Demography and Social Economy 2019;3(37):73-85. (in Ukrainian).

5. https://journals.indexcopernicus.com/search/details?id=320 39

6. da Costa JP, Vitorino R, Silva GM, Vogel C, Duarte AC, Rocha-Santos T. A synopsis on aging-Theories, mechanisms and future prospects. Ageing Res Rev. 2016;29:90-112. doi:10.1016/j.arr.2016.06.005 
7. Partridge L. Thenewbiologyofageing. Philos Trans R Soc Lond B Biol Sci. 2010;365(1537):147-154 doi:10.1098/rstb.2009.0222.

8. Goldsmith TC. Evolution of aging theories: Why modern programmed aging concepts are transforming medical research. Biochemistry Moscow. 2016;81:1406-1412 https://doi.org/10.1134/S0006297916120026

9. Ledberg A. Exponential increase in mortality with age is a generic property of a simple model system of damage accumulation and death. PLoS ONE. 2020;15(6): e0233384. https://doi.org/10.1371/journal.pone.0233384

10. Divo MJ, Martinez CH, Mannino DM. Ageing and the epidemiology of multimorbidity. European Respiratory Journal Oct 2014, 44 (4) 1055-1068. doi: 10.1183/09031936.00059814.

11. Bongaarts J. Human population growth and the demographic transition. Philos Trans R Soc Lond B Biol Sci. 2009;364(1532):2985-2990. doi:10.1098/rstb.2009.0137

12. Flatt T, Partridge L. Horizons in the evolution of aging.BMC Biol. 2018;16: e93. https://doi.org/10.1186/s12915-018-0562-z

13. Rukovodstvo po gerontologi i geriartrii: v 4-kh tomakh. Tom 3: Klinicheskaya geriatriya. Pod red. V.N. Yarygina A.S. Melent'yeva. GEOTAR-MEDIA. A guide to gerontology and geriatrics: in 4 volumes. Volume 3: Clinical Geriatrics. Ed. V.N. Yarygina A.S. Melentyev. GEOTAR-MEDIA 2010. 896 c. (In Russian). http://www.knidka.info/drugie-oblastimeditsiny/rukovodstvo-po-gerontologii-i-geriatrii-2/

14. Jónsson A, Gustafson YG, Hansen FR, Nygaard $H$, Valvanne J. et al. Geriatric rehabilitation as an integral part of geriatric medicine in the Nordic countries. Danish Medical Bulletin. 2003;50(4):439-445.

15. van Balen R, Gordon A.L, Schols JMGA. et al.What is geriatric rehabilitation and how should it be organized? A Delphi study aimed at reaching European consensus.EurGeriatrMed. 2019;10:977987.https://doi.org/10.1007/s41999-019-00244-7

16. Jónsson A, Gustafson YG,HansenFR, Nygaard $H$, Valvanne $\mathrm{J}$ et al. Geriatric rehabilitation as an integral part of geriatric medicine in the Nordic countries. Danish Medical Bulletin. 2003;50(4):439-45.

17. Sokolova NG. Physiotherapy. Rostov-on-Don: Phoenix, 2018. 350 p. (In Russian).

18. Skutin AV. Fizicheskaya reabilitatsiya $\mathrm{v}$ gerontologii: izbrannyye lektsii. Uchebno-metodicheskoye posobiye. Chelyabinsk. Skutin AV. Physical rehabilitation in gerontology: selected lectures. Study guide. Chelyabinsk. 2014. $147 \quad$ c. $\quad$ (In http://elib.cspu.ru/xmlui/handle/123456789/3598

19. Meinck M, Freigang, K, John B. et al. Wohnortnahe geriatrische Rehabilitation - Zur Struktur- und Prozessqualität eines mobilen und eines ambulanten Rehabilitationsmodells.Z Gerontol Geriat. 2002;35:463473. https://doi.org/10.1007/s00391-002-0065-x

20. Altuntaş O, Torpil B, Uyanik M. Occupational Therapy for Elderly People, Occupational Therapy - Occupation Focused Holistic Practice in Rehabilitation, Meral Huri,
Intech. 2017. doi: 10.5772/intechopen.69472. https://www.intechopen.com/books/occupational-therapyoccupation-focused-holistic-practice-inrehabilitation/occupational-therapy-for-elderly-people

21. Ustinova OI, Pimenov YuS, Ustinov YuV. Health of Healthy Humans: Historical Heritage of Academician N.M. Amosov on Achieving Good Health. World Journal of Medical Sciences. 2004;10(1):17-21. doi: 10.5829/idosi.wjms.2014.10.1.1138

22. Boolani A, Sur S, Yang D, Avolio A, Goodwin A, Mondal S. et al. Six Minutes of Physical Activity Improves Mood in Older Adults: A Pilot Study. Journal of Geriatric Physical Therapy: 2021;44(1):18-24. doi: 10.1519/JPT.0000000000000233.

23. Khrystova TE, Sukhanova AP. Osnovy likuval'noyi fizychnoyi kul'tury: navchal'nyy posibnyk dlya studentiv vyshchikh navchal'nykh zakladiv zi spetsial'nosti «Fizychne vykhovannya». Melitopol': TOV «Kolor Prynt». Hristova TE, Sukhanova AP. Fundamentals of therapeutic physical culture: a textbook for students of higher educational institutions in the specialty "Physical Education". Melitopol: Color Print LLC, 2015. 172 c. (in Ukrainian).

http://eprints.mdpu.org.ua/id/eprint/1946/1/\%D0\%9B\%D0 $\%$ A4\%D0\%9A.pdf

24. de Campos TF, Maher CG, Steffens D, Fuller JT, Hancock MJ. Exercise programs may be effective in preventing a new episode of neck pain: a systematic review and metaanalysis. J Physiother. 2018 Jul;64(3):159-165. doi: 10.1016/j.jphys.2018.05.003..

25. Suslina ZA, Varakin YuYa. Clinical guidelines for early diagnosis, treatment and prevention of vascular diseases of the brain. Moscow: MEDpress-inform, 2017. 352 p. (In Russian).

https://www.neurology.ru/sites/default/files/assets/documents/201 7/06/klinich-ruk-po-rannei-diagn-lech-prof-sosud-zab-golmozga.pdf?download $=1$

26. Osnovy reabilitatsiyi, fizychnoyi terapiyi, erhoterapiyi: pidruchnyk. Zahal'na redaktsiya L.O. Vakulenko, V.V. Klapchuka. - Ternopil': Ukrmedknyha:Ternopil'skyy derzhavnyy medychnyy universytet. Fundamentals of rehabilitation, physical therapy, occupational therapy: a textbook. General edition L.O. Вакуленко, B.B. Klapchuk. - Ternopil: Ukrmedknyha: Ternopil State Medical University 2018. 371 c. (in Ukrainian) https://library.gov.ua/osnovy-reabilitatsiyi-fizychnoyiterapiyi-ergoterapiyi/

27. Ponomareva IP, Prashchayeu KI. Palliative care in geriatrics: current issues and prospects. The Russian Archives of Internal Medicine. 2016;6(6):38-41. (In Russian). https://doi.org/10.20514/2226-6704-2016-6-6-38-41

28. Expanding the impact of cognitive behaviour therapy: A special edition in honor of G. Terence Wilson Expanding the impact of cognitive behaviour therapy: A special edition in honor of G. Terence Wilson. Edited by Carolyn Black Becker, Glenn Waller. Behaviour Research and Therapy. 2017;88:1-90.

https://www.sciencedirect.com/journal/behaviour-research-andtherapy/vol/88/suppl/C 